\title{
CONTROL ALgORITHMS FOR SERVICE AND INDUSTRIAL TRANSPORT ROBOTS
}

\author{
Aryskin Alexander, Bogdanovich Alena, Davydov Oleg, Grigoriev Aleksey, \\ Khelemendik Roman, Kharin Konstantin, Kuvshinov Sergey, Petrakov Maksim, \\ Plotnikov Aleksey, Pryanichnikov Valentin \& Tarasov Radomir.
}
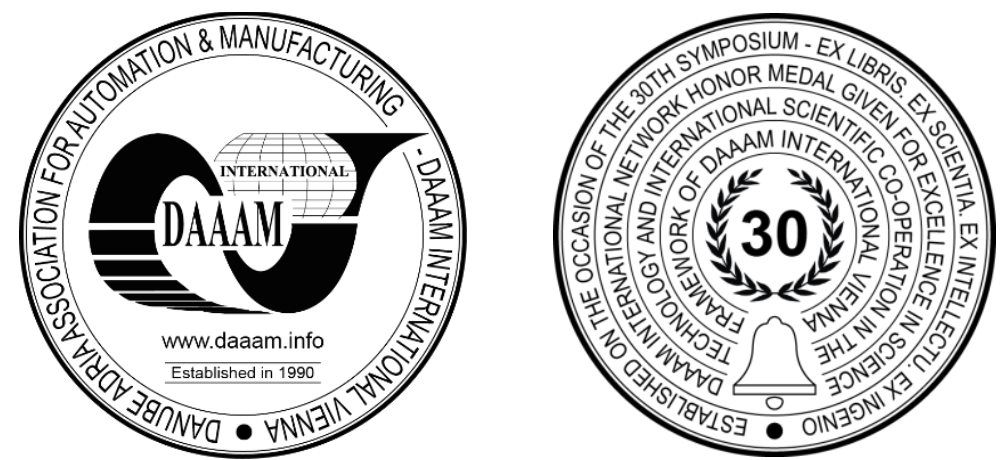

This Publication has to be referred as: Aryskin, A[lexander]; Bogdanovich, A[lena]; Davydov, O[leg]; Grigoriev, A[leksey]; Khelemendik, R[oman]; Kharin, K[onstantin]; Kuvshinov, S[ergey]; Petrakov, M[aksim]; Plotnikov A[leksey], Pryanichnikov, V[alentin]; \& Tarasov R[adomir] (2019). Control algorithms for service and industrial transport robots, Proceedings of the 30th DAAAM International Symposium, pp. 1166-1173, B. Katalinic (Ed.), Published by DAAAM International, ISBN 978-3-902734-22-8, ISSN 1726-9679, Vienna, Austria. DOI: 10.2507/30th.daaam.proceedings.164

\begin{abstract}
.
The paper is related with the design of the workshop and it's transport system according with the principles of concept Industry 4.0. At the stage of development and design of the transport system the main attention was required to be paid to the problem of accurate positioning. To organize timely stopping and accurate positioning of the heavy trolleys, it was decided to use an induction proximity switches with a special program for motion prediction and high-speed data processing by micro-PC. Also it is considered the problem of creating electronics to make a proper control for varies transport robots.
\end{abstract}

Keywords: Transport robotic systems, Industry 4.0, telemedical applications, sensorics, Amur-307.

\section{Introduction}

At the stage of development and design of the transport system, which is part of the industry 4.0 concept, the main attention was required to pay to the problem of the exact positioning of moving units within $5 \mathrm{~mm}$ and further changes of the motion direction. Based on the research, it was decided to use an induction proximity switches to organize timely stopping and accurate positioning of the trolleys up to 2 tons. The sensor part interacts with the scale "pulse ruler". To control the transport, it was necessary to assemble an automation equipment, build an enterprise structure including data transfer from the lower level to the upper, using various data protocols and developed software. This experience helped us also to develop on-board electronics for the Amur-307 service robot, which is part of the Amur complex for telemedical and another applications. Our main works are listed in [1-12].

\section{Design of a industrial transport for the workshop}

"Industry 4.0" has gained particular popularity in industrial centers of the world, primarily in China, USA, Germany, Japan, etc. Since 2014, the Russian Federation has also joined the modernization of its industrial sector, based on Federal Law 488 "on the new industrial policy". 
The transition to the concept of Industry 4.0 involves the computerization of the entire production environment. That means the technical integration of cyber-physical systems with production processes and logistics, as well as the active use of the Internet in production processes. All the ideas of the "Industry 4.0" initiative imply a high level of integration, trouble-free communications and, as a consequence, the integration of all means of production into a network. In this paper, we consider the transport system of the shop, included in the production line and working on the concept of "smart production" with deep logical analyses to prevent collision situations in men-PC interaction.

The work of the transport shop is based on mobile trolleys moving along the rails in the 4 directions and choosing of the stop-positions, depending on the performance of a particular operations on the production line. Each trolley is able to transport the material poured into it, to a certain place depending on the cycle of work, and finally return to the starting position. The company (in which we implement the shop) is producing the building materials "Tehfom". "Tehfom" is a heat-sound-insulating nonflammable material consisting of high-quality liquid sodium glass.

One of the main tasks of the design of the transport line, in the framework of this work, is the technological process associated with the solidification of the material in the carts during their passage along the conveyor in the drying chambers. This system has several zones of preparations and transportation of material (Fig1).

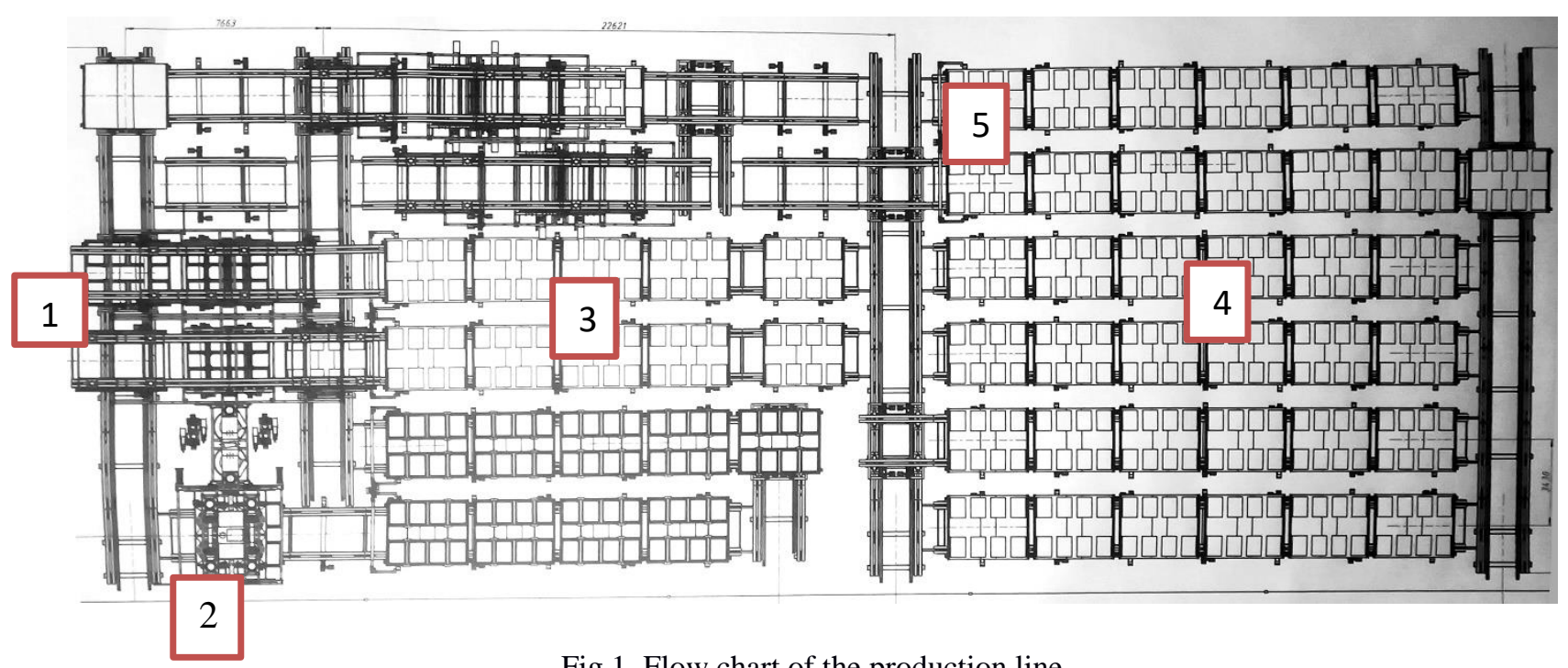

Fig.1. Flow chart of the production line

Position 1. Position of the preparation area of the filling mass, which prepares the transported mass for the trucks; Position 2. 4 reactors that pour liquid mass into the forms, working in 2 cycles of operation. At this stage each trolley is filled with a liquid mass; Position 3. Zone hardening of the mass in the trucks. At this stage, the carts are moved to the next destinations, during the passage of which the material solidifies; Position 4 . The drying position of the trolley, during the passage of which there is a drying of the poured mass; Position 5. Position of return of the cart to the initial state, i.e. to position 2, for filling of new filling mass;

This system consists of mechatronic subsystems, such as: bogies in conjunction with rail guides (Fig. 2), electric motors (Fig. 3), control systems, electronic power and control units, inductive sensors and measuring equipment (Fig.4).

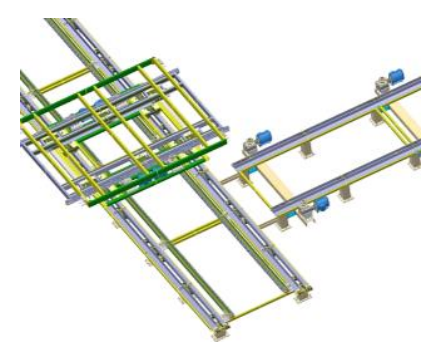

Fig.2. Rail guides

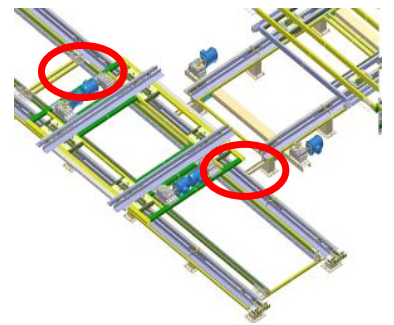

Fig.3. Electric motors



Fig.4. Inductive sensor

At the stage of development and design of this system, the main attention was required to pay to the problem of accurate positioning of mobile units within $5 \mathrm{~mm}$ and long-range change of direction. It was decided to use induction contactless switches, for the organization of timely stop and accurate positioning of the cart. The sensor part interacts with the scale of the " pulse ruler "(Fig. 5) This line is a rod with evenly distributed metal billets insulated with plastic polymer. 
The operation of this sensor is that the passage of the pulse line produces a number of signals transmitted to the local control device. This device in the course of mathematical analysis, sends a control command to the central programmable logic controller, where a signal is formed to accelerate or brake the engine.

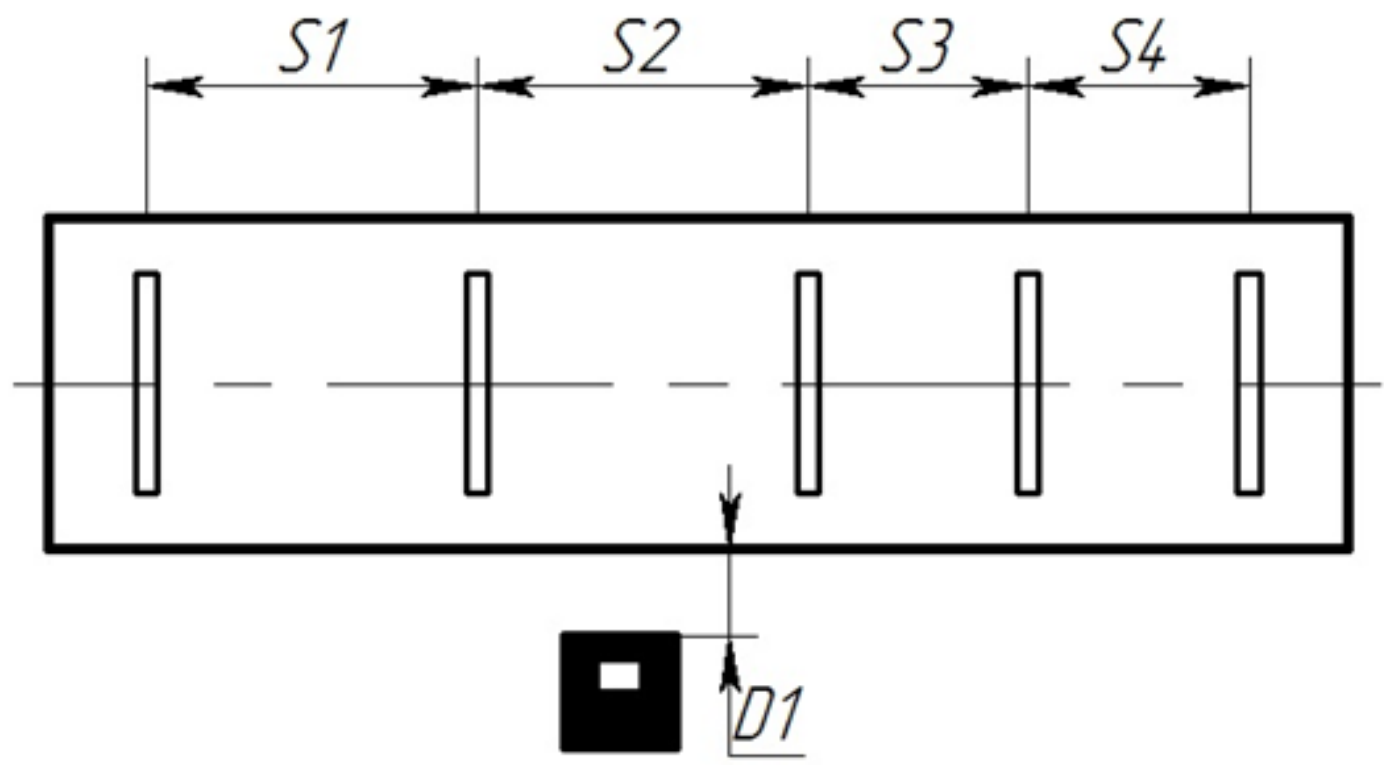

Fig.5. Sensor, made in the form of a ruler, and a contact device

In the presented image, S1-S4 is the distance between the "check points", D1 is the distance from the inductive sensor to the pulse ruler. To test the control of mobile units, a mathematical model was created in the program Matlab Simulink, the generated computer model is presented in (Fig.6).

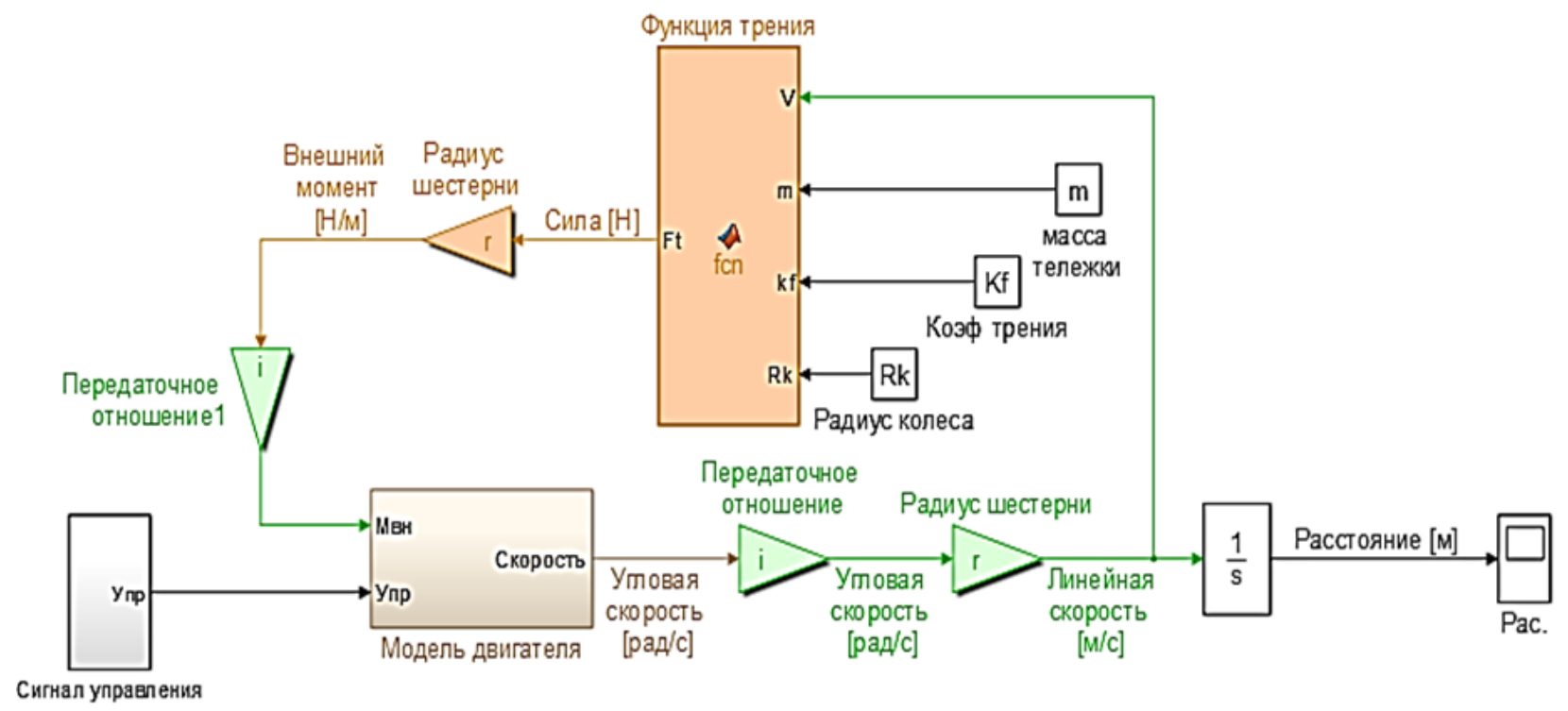

Fig.6. Computer model

The main blocks included in the mathematical model are: motor block friction function block, control signal block. The simulation of the system with the control step signal was carried out, the results are presented in (Fig.7). 

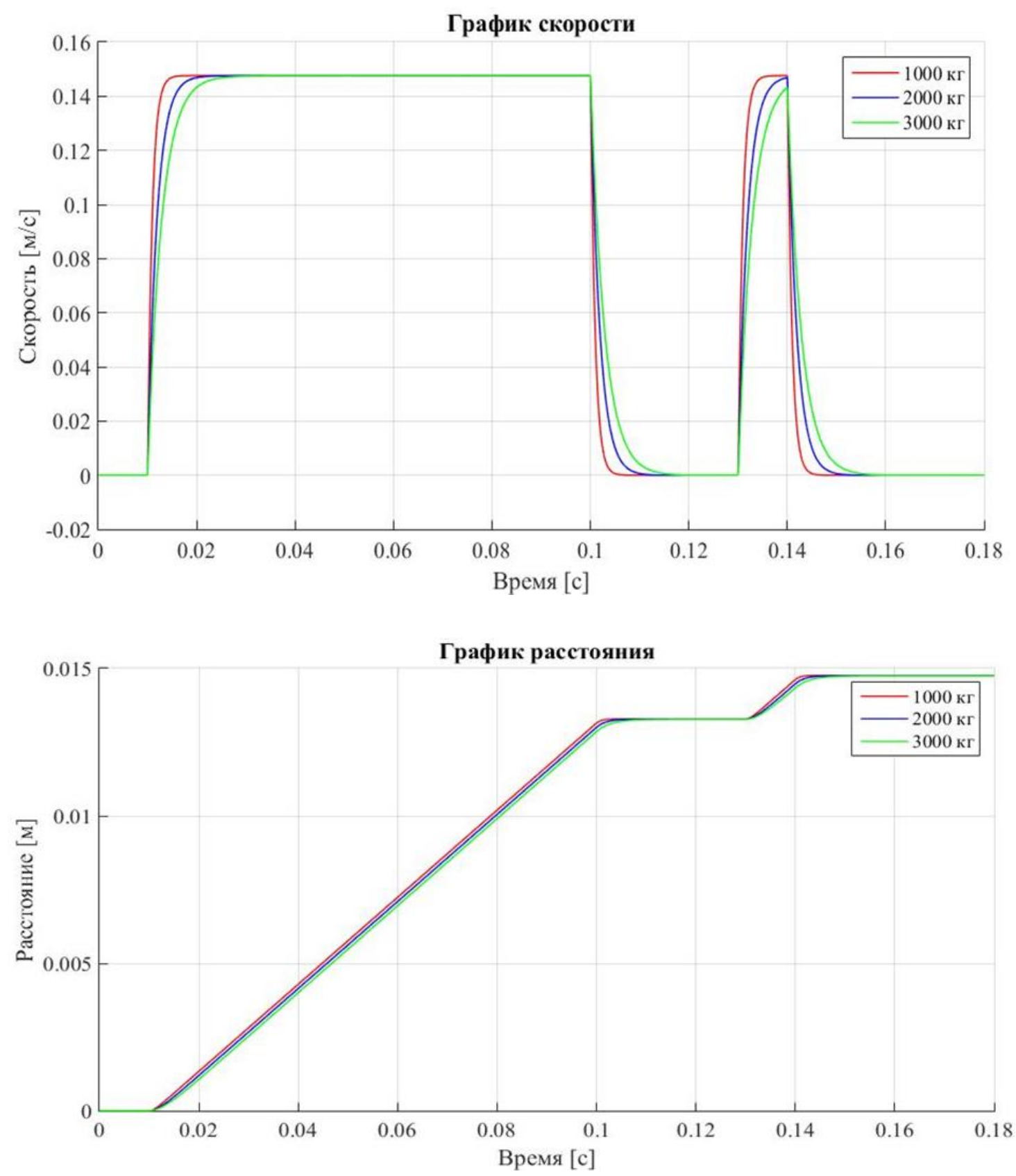

Fig.7. Graph of speed and distance at different weights of trucks

\begin{tabular}{|c|c|c|c|c|c|}
\hline $\begin{array}{l}\text { Weight } \\
{[\mathrm{kg}]}\end{array}$ & Speed $[\mathrm{mm} / \mathrm{s}]$ & $\begin{array}{l}\text { Final distance } \\
{[\mathrm{mm}]}\end{array}$ & $\begin{array}{l}\text { Breaking end } \\
\text { distance }[\mathrm{mm}]\end{array}$ & $\begin{array}{l}\text { Beginning of } \\
\text { deceleration }[\mathrm{mm}]\end{array}$ & Breaking $[\mathrm{mm}]$ \\
\hline 1000 & 147,6 & 147,6 & 132,8 & 132,8 & 0,15 \\
\hline 2000 & 147,56 & 147,5 & 132,8 & 132,8 & 0,29 \\
\hline 3000 & 147,51 & 147,4 & 132,7 & 132,7 & 0,43 \\
\hline
\end{tabular}

Table 1 . The results of the simulation

Based on the results of table 1. it is possible to draw a conclusion about influence of various parameters on system. Because of the too fast transition process, the braking of the cart is almost instantaneous, in consequence of which the braking distance is too small. A large influence on the positioning error in this case has a backlash in mechanical gears, which is quite difficult to model. To organize the automation of the industrial cycle was designed and assembled control equipment on the basis of industrial equipment PLC Owen. The exterior of the control Cabinet is shown in (Fig.8.) 

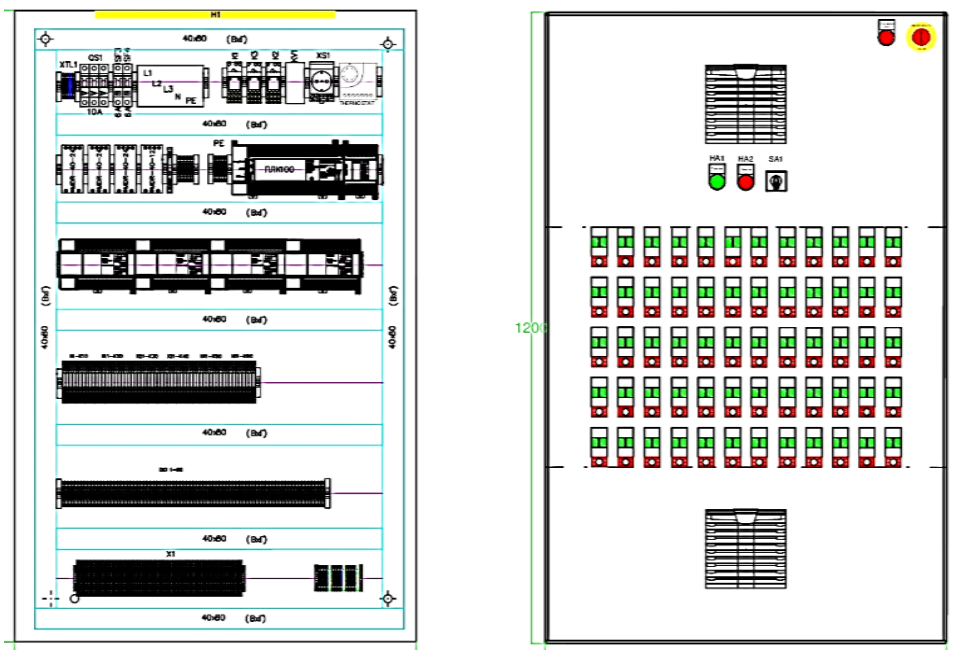

Fig. 8. Schematic diagram of the control equipment.

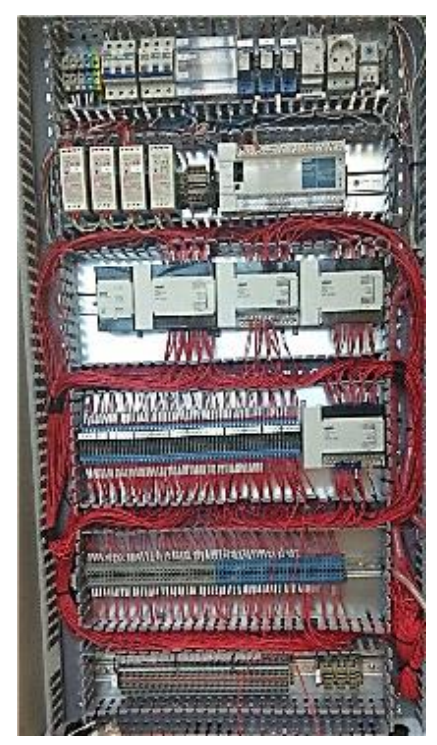

Fig.9. Assembled the automation equipment

The automation includes circuit breakers, 24V power supplies, diode decoupling, programmable logic controller with input and output expansion modules. The equipment allows both manual and automatic control. In manual mode it will automatically recording the button pressed by the operator and creating recipes. Simultaneously with the control of the production process, the industrial cycle is monitored by the operator [10]. Within the framework of this project, for the implementation of the set goals, a specialized environment for the development and debugging of software for programmable logic controllers - CODESYS will be considered.

The architecture of this enterprise is shown in (Fig.10).

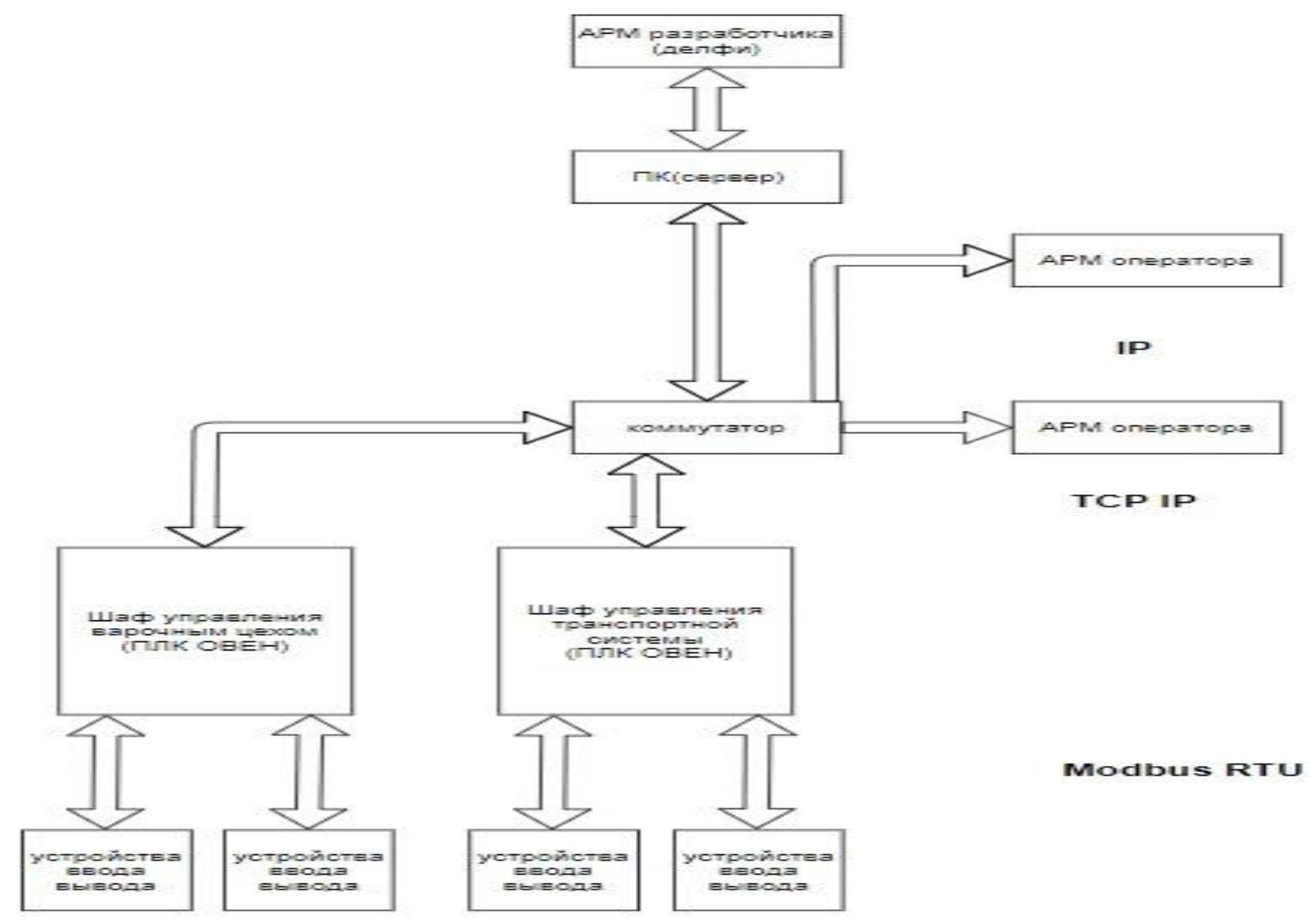

Fig.10. Enterprise architecture 


\section{Service robot developing: Amur-307}

The Amur-307 robot is designed to provide the necessary telecommunication capabilities for complex maintenance of internal premises of polyclinics [1]. This robot has a crawler drive and mounted custom manipulator with which the robot interacts with the surrounding objects [4]. Robot have the sensors: a wide-angle FullHD camera, six encoders for odometry and spatial orientation of the manipulator, a 9-axis inertial sensor, an atmospheric pressure sensor, lidar (RPLidar) and an ultrasonic sonar system. (Fig. 11)

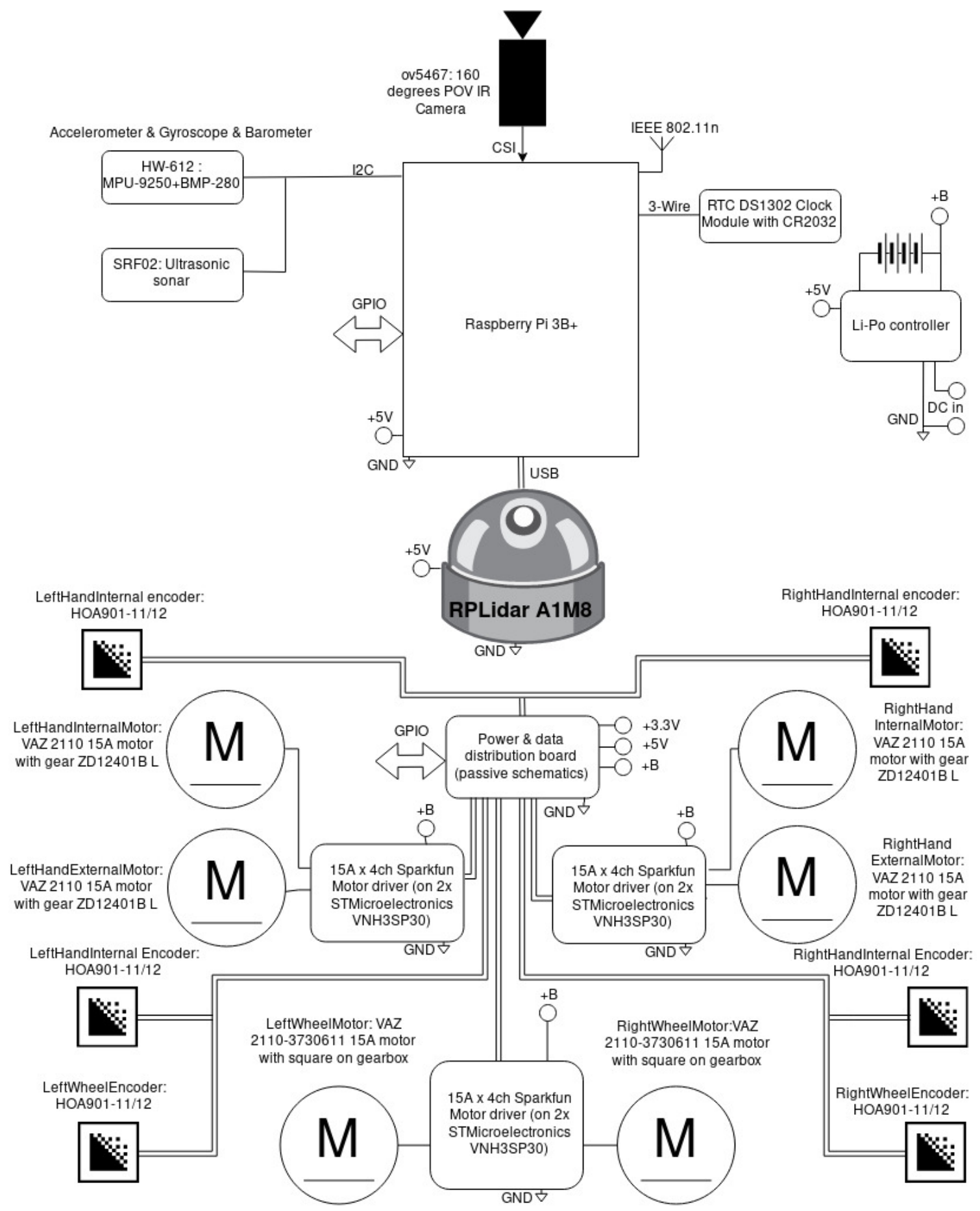

Fig.11. Block diagram of the electronics of the robot Amur-307

Raspberry Pi 3 B+ was chosen as a computing platform due to its cheapness, availability of a large number of projects supported by its community [6]. The Sparkfun Monster Moto Shield motor driver was chosen to control the motors due to the large adjustable current and cheapness. 
To ensure energy efficiency and simplicity of construction and power supply restrictions, the motors of the manipulator of different links were connected through a relay, thus of the two motors of the manipulator on each side at a particular time, only one works. Since the motors have a worm gear, when the motor is switched off, it does not change its axial position.

ADC modules (ADS1115) were also added, for processing current sensor readings of motor drivers, as well as for manipulator potentiometers. Since each motor driver requires independent PWM channels, it was decided to use a hardware implementation of DMA, since the raspberry Pi has only 2 hardware PWM ports.

Due to the increased number of input and output signal lines, two types of shift registers were used: parallel-to-serial to disable motor drivers and parallel-to-serial to connect encoders. Initially it was planned to put a multiplexer, but this solution was redundant and more expensive.

Since the raspberry Pi does not have a real-time clock system, it was decided to add an external real-time clock module (with battery). It's necessary as we use special program technology for making control algorithms stable in the conditions of delays in all channels [8].

To provide communication with other robots and/or with a stationary control and monitoring center, it was decided to use two channels: Wi-Fi (802.11 n) and radio protocol.

The robot is powered by an onboard lithium-polymer battery with stabilized voltages: $5 \mathrm{~V} / 2 \mathrm{~A}$ and $12 \mathrm{~V} / 10 \mathrm{~A}$ (maximum pulse current up to 550A), with a capacity of $12000 \mathrm{mAh}$.

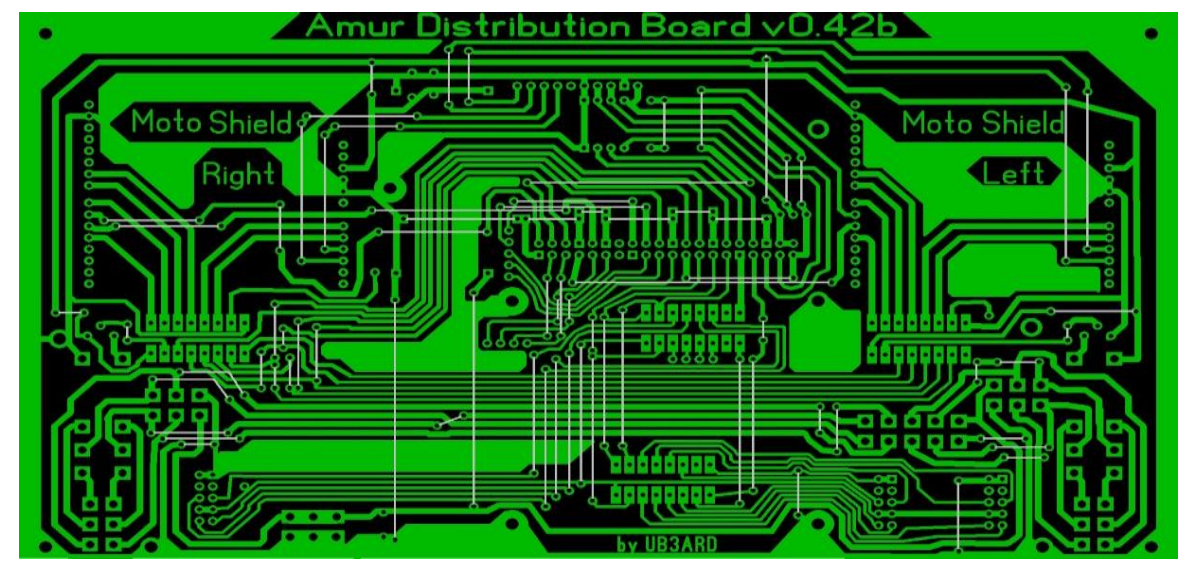

Fig.12. Appearance of the board with jumpers.

A prototype of the switching board for this robot was developed, which allows quick replacement of modules and other parts in case of malfunctions (Fig.12). Also in this PCB was installed a connector for motor switches, for the possibility of moving the robot in case of failure of the control electronics (only $12 \mathrm{~V}$ power is required). The layout diagram of the distribution board modules was also formed (Fig.13.).
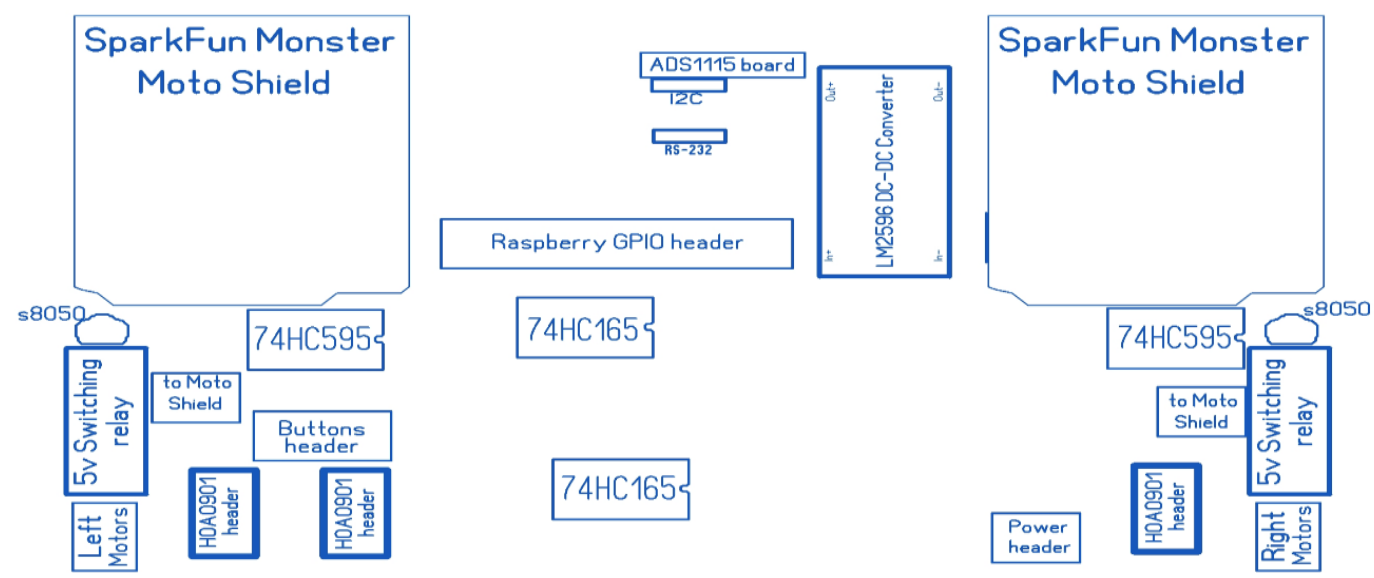

Fig.13. Layout of modules and parts on the board

The main results of the project "Intelligent robotronics" were tested and implemented in practice, also were published during last 3 years in 38 articles (14 Scopus), 2 patents and one Russian State Standard on robots and robotic devices (methods of programming and interacting with operators). Some of the references are below [1-14]. 


\section{Conclusion}

In the course of the work, the transport workshop system was designed and developed, implemented on the basis of the industry 4.0 concept. One of the main problems identified was the exact positioning of the trolley to change the direction of movement. Based on theoretical knowledge, in order to achieve the desired result, it was decided to develop a sensor made in the form of a ruler and a contact device. To control the workshop, an automation cabinet was built and the architecture of the enterprise was built, and the required software was written in the CoDeSys environment.

When designing electronics for the Amur-307 robot, which is part of the Amur telecommunications complex, a structural electrical circuit was formed [6]. A circuit diagram was also developed with the layout of the elements of the distribution board, with the subsequent implementation of the prototype.

\section{References}

[1] Pryanichnikov V.E., Katalinic B., Kirilchenko A.A., Khelemendik R.V., Kuvshinov S.V., Vician D., Uglesic A. New Creative Educational Technologies for Inter-university Network // 25th DAAAM International Symposium on Intelligent Manufacturing and Automation. 2014. — Procedia Engineering. 2015. — Vol. 100, — P.259-268. — URL: http://www.sciencedirect.com/science/article/pii/S1877705815003938

[2] Pryanichnikov V.E., Chernyshev V.V., Arykantsev V.V., Aryskin A.A., Eprikov S.R., Ksenzenko A.Ya., Petrakov M.S. (2018). Enhancing the Functionality of the Groups of Autonomous Underwater Robots, Proceedings of the 29th DAAAM International Symposium, pp.1319-1325, B. Katalinic (Ed.), Published by DAAAM International, ISBN 978-3-902734-20-4, ISSN 1726-9679, Vienna, Austria DOI: 10.2507/29th.daaam.proceedings. 190

[3] Pryanichnikov V. E., Bielic T., Vican D., Katalinich B., Kirsanov K. B., Kuvshinov S. V., Marzanov Yu., Poduraev J. V., Khelemendik R. V., Prysev E. A., Uglesic A., Kharin K.V. Development of educational technology and the network of associated laboratories of robotarium // Information-measuring and control system. - 2015. — Vol. 13, No. 7. - Pp. 7-25. ISSN 2070-0814.

[4] Shipovalov E. A., Pryanichnikov V. E. Auto-planning of missions of mobile robots by onboard computer complexes with hybrid architecture // Extreme robotics. / Collection of abstracts of the International scientific and technical conference. - St. Petersburg: Publishing and printing complex "Gangut", 2017. - Pp. 119-120.6.

[5] Kirilchenko A. A., Pryanichnikov V. E., Rogozin K. V. Limits of reliability and reliability of evidence. Skepticism in mathematics, functions, traditions // Information-measuring and control systems. - 2013. - Vol. 11, No. 4. Pp. 57-65. ISSN 2070-0814.

[6] Pryanichnikov V. E. Artificial intelligence and software and hardware robotic systems. Information-measuring and control systems. - 2018. - Vol. 16, No. 12. - Pp. 3-11. ISSN 2070-0814.

[7] Kuvshinov S. V., Pryanichnikov V. E., Khelemendik R. V., Kharin K. V., Eprikov S. R. Robotariums: scientific and technological base of "Intelligent robotronics" / / Information-measuring and control systems. - 2018. — Vol. 16, No. 12. Pp. 12-23. ISSN 2070-0814.

[8] Pryanichnikov V.E., Aryskin A.A., Eprikov S.R., Kirsanov K.B., Khelemendik R.V., Ksenzenko A.Ya., Prysev E.A., Travushkin A. S. (2017). Technology of Multi-Agent Control for Industrial Automation with Logical Processing of Contradictions, Proceedings of the 28th DAAAM International Symposium, pp.1202-1207, B. Katalinic (Ed.), Published by DAAAM International, ISBN 978-3-902734-11-2, ISSN 1726-9679, Vienna, Austria. DOI:10.2507/28th.daaam.proceedings. 167

[9] Pryanichnikov V.E., Ksenzenko A.Ya., Kuvshinov S. V., Poduraev Yu. V., Prysev E.A., Khelemendik R.V., Eprikov S. (2016). Intelligent robotronics: hardware-software complexes of robotariums, Proceedings of the 27th DAAAM International Symposium, pp.0225-0229, B. Katalinic (Ed.), Published by DAAAM International, ISBN 978-3902734-08-2, ISSN 1726-9679, Vienna, Austria, DOI: 10.2507/27th.daaam.proceedings.033

[10] Bogdanovich A.V., Kirsanov K.B., Pryanichnikov V.E., Khelemendik R.V. Hardware-Software components of intelligent service mobile robots / Information-measuring and control systems (Intelligent and adaptive robots, vol. 14, № 1-2, 2019), M.: Radiotechnika, 2018, vol. 16, № 12, p. 33-39. ISSN 2070-0814.

[11] Bogdanovich A.V., Kirsanov K.B., Khelemendik R.V., Pryanichnikov V.E., Prysev E.A. (2018). Development of Technology for Manufacturing Hardware and Intelligent Levels of the Service Autonomous Mobile Robot AMUR307, Proceedings of the 29th DAAAM International Symposium, pp.1313-1318, B. Katalinic (Ed.), Published by DAAAM International, ISBN 978-3-902734-20-4, ISSN 1726-9679, Vienna, Austria DOI: 10.2507/29th.daaam.proceedings.189

[12] Stepanova D., Pryanichnikov V.E., Khandorin S., Kuznetsov A., Koulchitskiy A. (2018). High-speed Image Processing Technique Implementation for Pointing and Tracking System Enabling Free-Space Optical Communications, Proceedings of the 29th DAAAM International Symposium, pp.1306-1312, B. Katalinic (Ed.), Published by DAAAM International, ISBN 978-3-902734- 20-4, ISSN 1726-9679, Vienna, Austria DOI: 10.2507/29th.daaam.proceedings. 188 